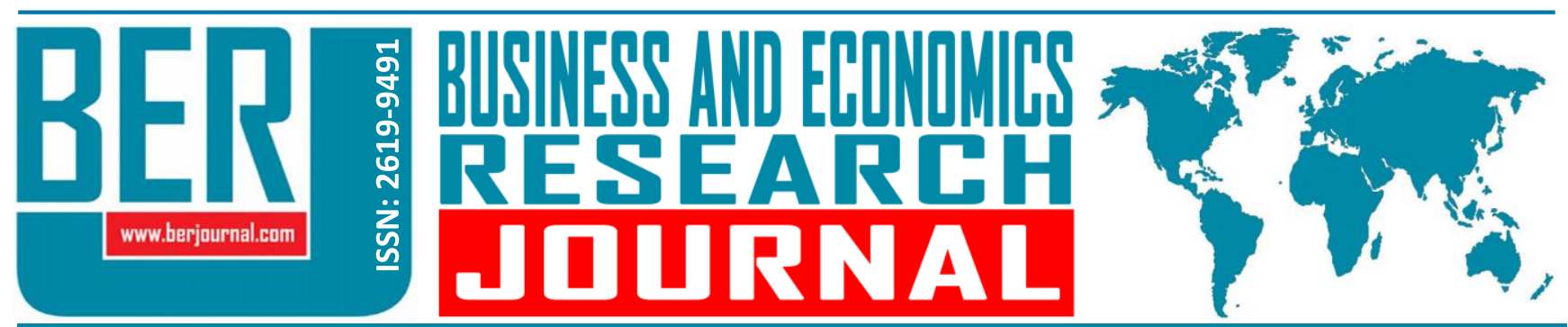

Business and Economics Research Journal Vol. 11, No. 2, 2020, pp. 545-554 doi: 10.20409/berj.2020.266

\title{
Dağıtım Adaletinin Çalışan Performansı Üzerindeki Etkisinde Algılanan Örgütsel Desteğin Aracı Rolü
}

\author{
Ergun Kara ${ }^{\mathrm{a}}$, Huseyin Aslan ${ }^{\mathrm{b}}$
}

Öz: Çalışan-örgüt etkileşiminde örgütsel prosedürler, örgütün çalışanlara yönelik tutumu ve çalışanların adalet algılarına yönelik vermiş oldukları tepki adalet algısının temellerini oluşturmaktadır. Genel olarak örgütsel verimliliğin sağlanabilmesi adına adalet algısının olumlu olması çalışanlardan elde edilecek verimi arttıracağından çalışanların performanslarının arttırılması için çalışan-örgüt etkileşiminde adalet uygulamalarının önemi her geçen gün artmaktadır. Bu nedenle, bu çalışmanın amacı dağıtımsal adaletin çalışan performansı üzerindeki etkisinde algılanan örgütsel desteğin aracılık rolünün araştırılmasıdır. Bu amaçla Gaziantep ilinde tekstil fabrikalarında çalışan 353 katılımcıdan anket aracılığıyla veri toplanmıştır. Ölçek geçerliliği için doğrulayııı faktör analizi yapılmış, değişkenler arası ilişkiler tespit edilmiş ve yapısal eşitlik modeli ile modelin uyum iyiliği testleri ve regresyon analizi yapılmıştır. Aracılık rolünü test edebilmek için ise dolaylı etkilerin anlamlılı̆ına bakılmış ve bunun için boostrap yöntemi kullanılmıştır. Yapılan analizlerde dağıtımsal adaletin algılanan örgütsel desteği pozitif yönde anlamlı olarak etkilediği tespit edilmiștir. Aracılık analizi neticesinde ise algılanan örgütsel desteğin dağıtımsal adalet ile çalışan performansı arasındaki ilişkide kısmi aracılık rolü olduğu tespit edilmiștir.

\section{The Mediating Role of Perceives Organizational Support on the Effect of Distribution Justice on Employee Performance}

Abstract: Organizational procedures in the interaction of employee-organization, attitude of the organization towards its workers and the reaction its workers give to justice perceptions establish the foundations of justice perception. In general, as justice perception's being positive will increase the productivity in workers in terms of providing organizational productivity, the significance of justice applications increase every other day in the employee-organization interaction to be able to enhance the performance of workers. Therefore, the aim of this study is to investigate the mediating role of perceived organizational support in the effect of distributive justice on employee performance. For this reason, data was collected from 353 participants working in textile factories in Gaziantep through questionnaire. Confirmatory factor analysis was performed in the analysis of the data, correlations between the variables were determined, and structural equation and goodness of fit tests of the model and regression analysis were performed. In order to test the mediating role, the significance of the indirect effects was examined using the bootstrap method. In the analyses, it was determined that distribution justice had a significant positive effect on perceived organizational support. As a result of mediating analysis perceived organizational support was found to have a partial mediator role in the relationship between distribution justice and employee performance.

Anahtar Sözcükler: Dağıtım Adaleti, Örgütsel Destek, Çalışan Performansı

JEL: D23, M10

$\begin{array}{ll}\text { Geliş } & : 13 \text { Ocak } 2020 \\ \text { Düzeltme } & : 17 \text { Şubat } 2020 \\ \text { Kabul } & : 12 \text { Mart } 2020 \\ \text { Tür } & : \text { Araştırma }\end{array}$

Keywords: Distributive Justice, Perceived Organizational Support Employee Performance

JEL: D23, M10

Received : 13 January 2020

Revised : 17 February 2020

Accepted : 12 March 2020

Type : Research

a Asst. Prof., PhD., Osmaniye Korkut Ata University, Faculty of Economics and Administrative Sciences, Osmaniye, Turkiye, ergunkara@osmaniye.edu.tr (ORCID ID: 0000-0002-7815-1111)

b Asst. Prof., PhD., Osmaniye Korkut Ata University, Faculty of Economics and Administrative Sciences, Osmaniye, Turkiye, huseyinaslan111@gmail.com (ORCID ID: 0000-0002-0547-1317) 


\section{Giriş}

Çalışan-örgüt etkileşiminde örgütsel yönetim prosedürleri ile örgütün çalışanlara yönelik tutumu ve çalışanların adalet algılarının olumsuz ya da olumlu olması çalışanların adalet algısının temelini oluşturmaktadır. Önemi her geçen artan adalet algısı çalışanların tutum ve davranışlarını etkileyen önemli örgüt içi faktörlerden biridir (Kalay, 2016). Bu doğrultuda çalışanların faaliyetlerine ilişkin elde ettikleri kazanımların değerlendirilmesinde kendilerine ne derece adil davranıldığı ya da davranılmadığına yönelik adalet algıları, çalışanların performanslarının artmasında ya da azalmasında adalet algısının önemini ortaya koymaktadır.

Adalet uygulamalarının çalışanlar nezdinde olumlu veya olumsuz şekilde algılanması çalışanların tutum ve davranışlarını değiştirmektedir. Genel olarak adalet algısı çalışanların iş tatmini (Ouyang, Sang, Li ve Peng, 2015; Kim ve Chung, 2019), örgütsel bağlılık (Suliman ve Al Kathairi, 2012; Crow, Lee ve Joo, 2012), örgütsel vatandaşlık davranışı (Polat ve Celep, 2008; Zeinabadi ve Salehi, 2011), işten ayrılma niyeti (Ponnu ve Chuah, 2010; Aslan ve Uçar, 2015) ve tükenmişlik (Yeniçeri, Demirel ve Seçkin, 2009; Meydan, Basım ve Çetin, 2011) düzeylerini etkilemektedir. Dolayısıyla örgütsel verimlilik açısından adalet algısının olumlu olması çalışanlardan elde edilecek verimi arttıracağı için çalışanların performanslarının arttırılması için çalışan-örgüt etkileşiminde adil adalet uygulamalarının önemi artmaktadır. Nitekim yapılan çalışmalarda da olumlu adalet algısının çalışanların performanslarını arttırdığı görülmektedir (Wayne, Shore, Bommer ve Tetrick 2002; DeConinck, 2010; Mitchell, Gagné, Beaudry ve Dyer, 2012). Çalışanların performanslarının arttırılmasında bir diğer önemli etken ise algılanan örgütsel destektir. Algılanan örgütsel destek seviyesi yüksek olan çalışanlar genel olarak örgütün amaçlarına katkıda bulunmada diğer çalışanlara karşın daha istekli davranış sergilemekte ve örgüte karşı daha yüksek düzeyde bağlılık davranışı sergilemektedirler. Ayrıca algılanan örgütsel destek seviyesi yüksek olan çalışanlar örgütsel faaliyetlere ilişkin göstermiş oldukları çabanın karşılığında elde ettikleri faydanın artacağı düşüncesiyle daha yüksek düzeyde iş performansı sergilemektedirler (Neves ve Eisenberger, 2012). Yapılan çalışmalarda da algılanan örgütsel desteğin çalışanların performanslarını pozitif yönde etkilediği görülmektedir (Turunç ve Çelik, 2010; Chiang ve Hsieh, 2012; Uppal, 2017).

Dağıtımsal adalet ve algılanan örgütsel desteğin çalışan performansı üzerindeki olumlu etkisi ve dağıtımsal adaletin çalışan performansı üzerindeki etkisinin arttırılmasında ise algılanan örgütsel desteğin artırıcı bir etkisinin olup olmadığı bu çalışmanın çıkış noktasını oluşturmaktadır. Literatürde dağıtımsal adaletin çalışanların performansı üzerindeki etkisi her ne kadar araştırılsa da algılanan örgütsel desteğin bu etkideki rolünün araştırılmaması ise bu araştırmanın önemini ortaya koymaktadır.

Çalışma nezdinde oluşturulan araştırma soruları ise şu şekildedir:

- Dağıtımsal adalet algılanan örgütsel desteği etkilemekte midir?

- Dağıtımsal adaletin çalışan performansı üzerindeki etkisinde algılanan örgütsel desteğin aracılık rolü bulunmakta mıdır?

Bu açıdan araştırmanın bundan sonraki kısmında kavramlar arasındaki ilişkiler açıklanarak yapılan alan araştırması ile çalışma hipotezleri test edilmiş ve sonuç ve çıkarımlar kısmında ise elde edilen bulgular, uygulayıcılar ve bundan sonra yapılan yapılacak çalışmalara da ışık tutacak şekilde tartışılmıştır.

\section{Literatür Taraması ve Hipotezlerin Oluşturulması}

Örgütsel adalet boyutlarından olan dağıtım adaleti, çalışanların iş çıktılarının dağıtılmasında örgütün adil dağıtım prosedürü uygulayıp uygulamadığı algılaması ile ilgilidir (Greenberg ve Baron, 2000: 44). Dağıtım adaleti, işletmeler tarafından çalışan personele verilen ücret, ödül, ceza ve terfi gibi kazanımların çalışan bireyler tarafından adaletli olarak algılanması anlamına gelmektedir. Dağıtım adaleti, örgütte çalışan bireylerin işletme lehine başarılı davranış göstermeleri durumunda belirli ödüllere sahip olabileceklerini garanti etmektedir (İşcan ve Naktiyok, 2004: 183). Dağıtım adaleti, genel olarak yapılan iş ve işlemlerde sonuca yönelik tarafsızlığın algılanmasını temsil etmektedir. Durum bu yönüyle ele alındığında, dağıtım adaletinin işletmelerde çalışanların bireylere verilecek olan ücret ve terfi gibi motivasyonu yükseltecek 
konularla ilgili algılarını belirlediği ifade edilebilir (İçerli, 2010: 79). Dağıtım adaleti gerek ahlaki gerekse nesnel olarak bireylere yönelik tanımlanan özellikler çerçevesinde, birbirleriyle benzerlik gösteren çalışanlara aynı davranılmasını ancak farklı olanlara ise farklı şekillerde davranılmasını açıklar (Foley, Kidder ve Powell, 2002: 473-474). Dağıtım adaleti her zaman sonuç odaklı çalışmaktadır. Böylelikle sonuçlara gösterilen birtakım duygusal ve davranışsal tepkiler ortaya çıkmaktadır. Örgütlerde karar olarak alınan bazı sonuçların çalışan bireyler tarafından adaletsiz olarak algılanması neticesinde mevcut çalışan bu durumdan olumsuz olarak etkilenmektedir (Cohen-Charash ve Spector, 2001). Nihayet dağıtım adaleti, örgütlerde çalışan bireylerin tutum ve davranışlarını belirlemede çok önemli bir etkendir (Clay-Warner, Reynolds ve Roman, 2005).

Algılanan örgütsel destek ise örgütün çalışanların fikir ve duygularına ne derece önem verdiği ve çalışanların refahını ne derece önemsediğine dair algılamalarıdır (Rhoades ve Eisenberger, 2002; Rhoades ve Eisenberger, 2002) Şeklinde düzeltilmiştir. "Algılanan örgütsel destek, işletmeler tarafından çalışanların örgüte sağladıkları katkılarının ne derece önemli olmasıyla ilgili bir durumdur. Algılanan örgütsel destek ile çalışanların işe olan devamlarında bir azalma görülüyorsa ve de örgütün beklentilerine yönelik olarak çalışanların sundukları katkı artıyorsa bunun neticesinde bir ödüllendirme sisteminin olabileceğini dikkate almaktadır" (Eisenberger vd., 1986: 500).

Sosyal değişim teorisi çerçevesinde gerek ekonomik fayda odaklı etkileşim ile gerekse de sosyoduygusal ihtiyaçların karşılanmasına yönelik olarak çalışan-örgüt etkileşiminde olumlu adalet algısının algılanan örgütsel desteği etkilediği görülmektedir (Ambrose ve Schminke, 2003; Cropanzano, Prehar ve Chen, 2002). Eisenberger vd.'ye (1986) göre algılanan örgütsel destek adil muamele ile bağlantılıdır. Shore ve Shore (1995) bu durumu kaynakların dağılımındaki adil olma ile ilişkilendirerek dağıtım adaletinin algılanan örgütsel desteğin bir belirleyicisi olduğu şeklinde ifade etmiştir. Cheung ve Law (2008) ise bu durumu iş yerinde ücrete yönelik olumlu adalet algısının çalışan-örgüt etkileşiminde önemli bir etken olabileceği şeklinde belirtmiştir. Loi, Hang-Yue ve Foley (2006) ise çalışan-örgüt etkileşiminde dağıtım adaletinin çalışanların sosyo-duygusal intiyaçların karşılanmasına yönelik olarak algılanan örgütsel desteği etkilediğini belirtmektedir. Dağıtım adaleti ve algılanan örgütsel destek arasındaki ilişkiyi belirlemeye yönelik yapılan çalışmalarda ise dağııım adaleti ve algılanan örgütsel destek arasında pozitif yönlü bir ilişkinin olduğu görülmektedir (Wayne, Shore, Bommer ve Tetrick, 2002; DeConinck, 2010; Mitchell, Gagné, Beaudry ve Dyer, 2012). Bu doğrultuda yukarıda belirtilen teori ve çalışma bulgularından yola çıkarak dağıtım adaleti ile algılanan örgütsel destek arasındaki ilişkiyi belirlemeye yönelik aşağıdaki hipotez oluşturulmuştur;

H1. Dağıtım adaleti algılanan örgütsel desteği pozitif yönde etkilemektedir.

Çalışan performansı kavramı ise, günümüzde faaliyet gösteren tüm işletmelerin yakından ilgilenmesi gereken temel bir kavramdır. Çalışan performansı kavramı ise, günümüzde faaliyet gösteren tüm işletmelerin yakından ilgilenmesi gereken temel bir kavramdır. Özelikle de işletmelerin rakip işletmelere karşı görece üstünlük sağlamaları için çalışan performansı önemli bir etkendir (İraz ve Akgün, 2011: 228). Örgütte çalışan bireyler görev yaptıkları işletmelere örgütsel anlamda bir bağlıık olması nedeniyle performansları örgütün performansına direkt etki yapacaktır (Başa, 2019: 49).

Dağıtım adaleti ve çalışan performansı arasındaki ilişki ise Wang, Liao, Xia ve Chang (2010)'a göre Adams'ın (1965) eşitlik teorisine dayanmaktadır. Nasurdin ve Khuan'a (2007) göre eşitlik teorisine göre çalışanlar elde ettikleri kazanımları eşitlik temelinde diğer çalışanların kazanımlarıyla karşılaştırmaktadırlar ve bu karşılaştırmada eşitsizlik algıladıklarında tutum ve davranışlarını değiştirerek iş rollerine devam etmektedirler. Başka bir ifade ile çalışanların çabaları karşılı̆ı elde ettikleri kazanımların adil olmaması durumunda çalışanlar daha az çaba harcamaktadırlar (Haar ve Spell, 2009). Choi'ye (2011) göre çalışan-örgüt etkileşiminde adil adalet algısı yönetime ve örgüte güven duygusunu geliştirmekte ve böylece çalışanlar adil adalet algısına karşılık daha fazla performans göstermektedirler. Dağıtım adaleti ile çalışan performansı arasındaki ilişkiyi belirlemeye yönelik yapılan çalışmalarda ise dağııım adaleti ile çalışan performansı arasında pozitif yönlü bir ilişkinin olduğu görülmektedir (Nasurdin ve Khuan,2007; Suliman ve Al Kathairi, 2012; Sökmen, Bilsel ve Erbil, 2013).

Sosyal değişim teorisi çerçevesinde çalışanlar performanslarını örgütsel kazanımlara göre arttırabilir veya azaltabilirler (Kaplan ve Öğüt, 2012). Çalışan-örgüt etkileşiminde çalışanların örgütsel faaliyetlere ilişkin 
olarak göstermiş oldukları çabalarının faydalı olduğu inancının olması çalışanların bu faydaya performans ile karşılık vermelerine neden olur (Rhoades ve Eisenberger, 2002; Turunç ve Çelik, 2010). Algılanan örgütsel destek ile çalışan performansı arasındaki ilişkiyi belirlemeye yönelik yapılan çalışmalarda da algılanan örgütsel destek ile çalışan performansı arasında pozitif yönlü bir ilişkinin olduğu görülmektedir (Turunç ve Çelik, 2010; Chiang ve Hsieh, 2012; Uppal, 2017).

Yukarıda yer alan teori ve çalışma bulguları ışığında dağıtımsal adaletin çalışan performansı üzerindeki etkisinde algılanan örgütsel adaletin artırıcı etkisinin olduğu düşünülmektedir. Bu doğrultuda aşağıdaki hipotez oluşturulmuştur;

H2. Dağıtım adaletinin çalışan performansı üzerindeki etkisinde algılanan örgütsel desteğin aracı rolü vardır.

Literatür ve hipotezler doğrultusunda, değişkenler arası ilişkileri ortaya çıkarmak amacı ile Şekil 1'de gösterilen model oluşturulmuştur.

Şekil 1. Araştırma Modeli

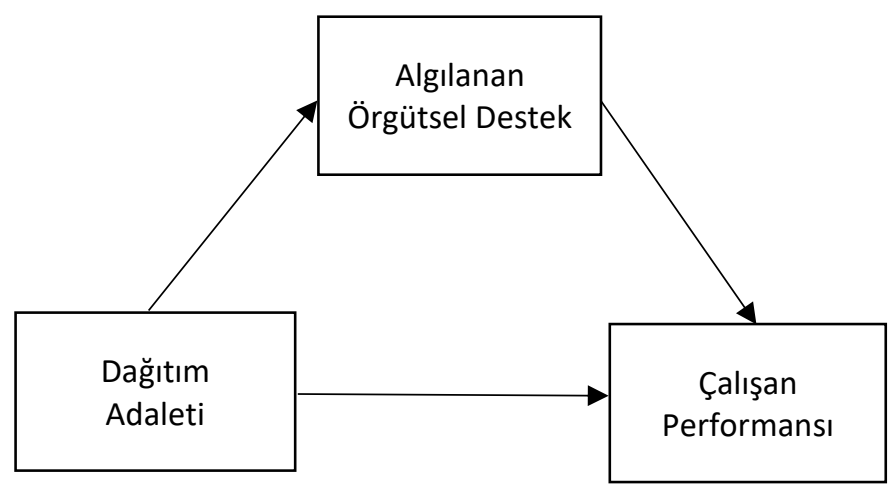

\section{Araştırmanın Yöntemi}

\subsection{Araştırmanın Evreni ve Örneklemi}

Dağıtım adaletinin çalışan performansı üzerindeki etkisinde algılanan örgütsel desteğin aracı rolünü belirlemeye yönelik olan bu araştırmanın evrenini Gaziantep ilindeki üretim firmaları oluşturmaktadır. Araştırmanın örneklemi ise kolayda örnekleme yöntemiyle seçilmiş Gaziantep ilindeki tekstil firmaları çalışanlarıdır. Zaman ve maliyet sınırııı̆ından dolayı rastgele seçilmiş olan 10 adet tekstil işletmesinde çalışan 450 kişiye anket yapılması planlanmıştır. Örneklemin tekstil işletmeleri olarak seçilmesinin nedeni ise Gaziantep sanayisi içerisindeki üretim hacminin diğer sektörlerden daha fazla olması ve tekstil üretim işletmelerindeki ücret ve gelir dağılımlarının gerek işletme içi gerekse de sektördeki dengesizliklerin diğer üretim işletmelerine nazaran daha fazla olmasıdır. Dağıtılan anketlerin 54'ü cevaplandırılmamış, 43'ünda ise eksik cevaplandırma olduğu için araştırmanın örneklemi 353 kişiden oluşmaktadır. Çalışanların 98'i kadın $255^{\prime} i$ ise erkektir. Çalışanların 96 'sı $18-29$ yaş, $185^{\prime}$ i $30-40$ yaş ve 72 'si ise 41 ve üzeri yaş aralığında yer almaktadır. İ̧̧ deneyimi açısından çalışanların $74^{\prime}$ ü $1-4$ yıl, $138^{\prime} i$ 5-10 yıl ve $141^{\prime} i$ ise 11 yıl ve üzeri iş tecrübesine sahiptir.

\subsection{Araştırmanın Ölçekleri}

Dağıtım Adaleti Ölçeği: Niehoff and Moorman (1993) tarafından geliştirilen ve Türkçe geçerlemesi Gürbüz and Mert (2009) tarafından yapılan ve beş maddeden oluşan ölçek kullanılmıştır. Bu çalışmada ölçeğin Cronbach alfa güvenirlik katsayısı 0,94 olarak tespit edilmiştir. 
Örgütsel Destek Ölçeği: Rhoades vd. (2001) tarafından geliştirilen ve Türkçe geçerlemesi Çınar (2013) tarafından yapılan ve beş maddeden oluşan ölçeğin kısa hali kullanılmıştır. Bu çalışmada ölçeğin Cronbach alfa güvenirlik katsayısı 0,96 olarak tespit edilmiştir.

Çalışan Performansı Ölçeği: Sigler ve Pearson (2000)' ın, Kirkman ve Rosen (1999) çalışmasından uyarladığı tek boyut ve dört maddeden oluşan ölçek kullanılmıştır. Ölçeğin Türkçe uyarlaması Çöl (2008) tarafından yapılmıştır. Bu çalışmada ölçeğin Cronbach alfa güvenirlik katsayısı 0,96 olarak tespit edilmiştir.

\section{Bulgular}

Araştırma verileri SPSS ve AMOS paket programları ile analiz edilmiştir. Yapısal geçerliliği test etmek için ölçeklere ve araştırma modeline yönelik doğrulayıcı faktör analizleri yapılmış ve model ve ölçek verilerinin kabul edilebilir uyum gösterdiği tespit edilmiştir (Gürbüz ve Şahin, 2016; Meydan ve Şeşen, 2015).

Tablo 1. Ölçeklerin ve Araştırma Modelinin Uyum İyiliği İstatistikleri

\begin{tabular}{lcccccccc}
\hline Uyum İyiliği Değerleri & $\mathbf{X}^{2}$ & $\mathbf{d f}$ & $\begin{array}{c}\text { CMIN } \\
\text { /DF }\end{array}$ & SRMR & IFI & CFI & TLI & RMSEA \\
\hline Dağııım Adaleti & 11,057 & 4 & 2,764 & 0,007 & 0,997 & 0,997 & 0,992 & 0,071 \\
\hline Algııanan Örgütsel Destek & 15,111 & 5 & 3,022 & 0,007 & 0,995 & 0,995 & 0,991 & 0,076 \\
\hline Çalışan Performansı & 4,946 & 2 & 2,473 & 0,005 & 0,998 & 0,998 & 0,995 & 0,065 \\
\hline Ölçüm Modeli & 175,330 & 74 & 2,369 & 0,001 & 0,984 & 0,984 & 0,981 & 0,062 \\
\hline
\end{tabular}

Değişkenler arasındaki korelasyon değerleri ve değişkenlere ait güvenirlilik değerleri, çarpıklık ve basıklık değerleri ve betimleyici istatistik değerleri Tablo 2'de yer almaktadır. Çarpıklık ve basıklık değerleri 2 ile +2 arasında yer aldığı için veriler normal dağılım göstermektedir. Yine Tablo 2 incelendiğinde, dağıtım adaleti ile algılanan örgütsel destek ve çalışan performansı arasında ve algılanan örgütsel destek ile çalışan performansı arasında pozitif yönde bir ilişkinin olduğu görülmektedir.

Tablo 2. Betimleyici İstatistikler ve Korelasyon Katsayıları

\begin{tabular}{lccccccc}
\hline & Ort. & Ss. & Çarpıklık & Basıklık & $\mathbf{1}$ & $\mathbf{2}$ & $\mathbf{3}$ \\
\hline 1. Dağııım Adaleti & 3,25 & 1,31 & $-0,66$ & $-0,92$ & & & \\
\hline 2. Algılanan Örgütsel Destek & 3,86 & 1,15 & $-1,33$ & 0,55 & $0,466^{* *}$ & & \\
\hline 3. Çalışan Performansı & 3,55 & 1,01 & $-1,08$ & 0,14 & $0,430^{* *}$ & $0,580^{* *}$ & \\
\hline
\end{tabular}

$* * p<0,001, n=353$

Araştırmanın bundan sonrakı kısmında ise araştırma hipotezlerinin test edilebilmesi için Şekil 2'de yer alan yapısal eşitlik modeli kurulmuştur. Aracılık rolünün testi için dolaylı etkilerin anlamlılığına bakabilmek için monte carlo parametrik boostrap seçeneği ile 5000 örneklemden oluşan \%95 güven aralığında en yüksek olabilirlik yöntemi kullanılmıştır. Güven aralıklarına ilişkin alt ve üst değerleri Tablo 3'te sunulmuştur.

Yapısal model üzerinden araştırma hipotezleri test edilmiştir. Araştırma modeli uyum iyiliği değerlerini sağlamaktadır $(\chi 2 / d f=2,36 ; \mathrm{SRMR}=0,01 ; \mathrm{IFI}=0,98 ; \mathrm{TLI}=0,98 ; \mathrm{CFI}=0,98 ; \mathrm{RMSEA}=0,06)$. Analiz neticesinde dağıtımsal adalet algılanan örgütsel destek üzerinde $(\beta=0,479, p<0,001, \% 95 \mathrm{Cl}[0,37,0,58])$ pozitif yönde anlamlı bir etkiye sahiptir. Bu durumda $\mathrm{H} 1$ hipotezi desteklenmiştir. Algılanan örgütsel destek ise çalışan performansı üzerinde $(\beta=0,510, p<0,001, \% 95 \mathrm{Cl}[0,38,0,61])$ pozitif yönde anlamlı bir etkiye sahiptir. Yine dağıtımsal adalet çalışan performansı üzerinde toplam $(\beta=0,447, p<0,001, \% 95 \mathrm{Cl}[0,35,0,54])$ ve doğrudan $(\beta=0,205, p<0,001, \% 95 \mathrm{Cl}[0,12,0,30])$ pozitif yönde anlamlı bir etkiye sahiptir. Ayrıca 
dağıtımsal adaletin çalışan performansı üzerinde dolaylı $(\beta=0,242, p<0,001, \% 95 \mathrm{Cl}[0,17,0,32])$ anlamlı etkisinin olduğu bulunmuştur. Bu durumda $\mathrm{H} 2$ hipotezi desteklenmiştir. Bu bulgulara göre dağıtımsal adaletin çalışan performansı üzerindeki etkisinde algılanan örgütsel desteğin kısmi aracılık rolü vardır. Zira elde edilmiş Boostrap güven aralığı değerleri 0 (sıfır) değerini kapsamamaktadır.

Şekil 2. Yapısal Eşitlik Modeli

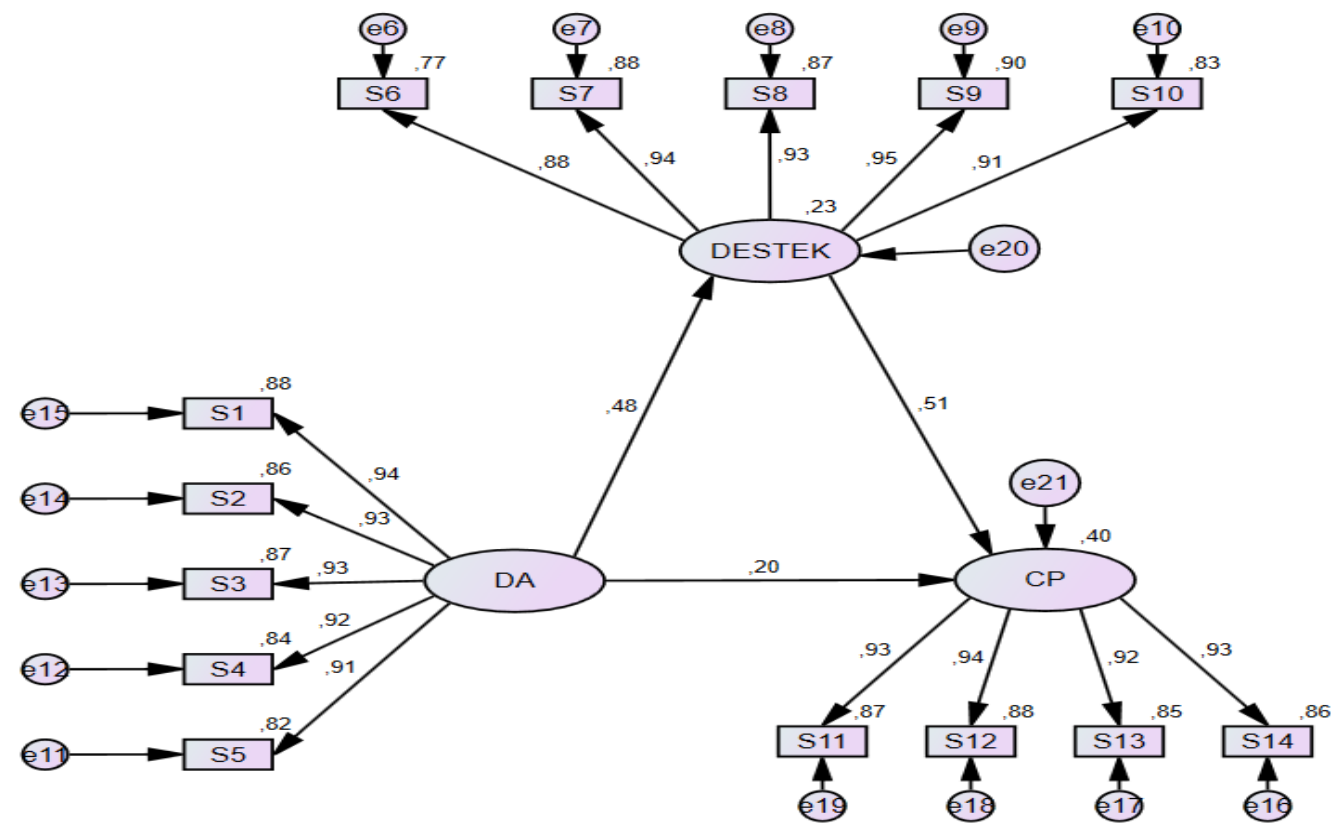

Tablo 3. Aracılık Analizi

\begin{tabular}{ccccccc}
\hline \multicolumn{2}{r}{ Test Edilen Yol } & & \multirow{2}{*}{ SE } & \multicolumn{2}{c}{ YD \%95 GA } \\
\cline { 3 - 6 } Dağıtımsal Adalet & $--->\begin{array}{l}\text { Algılanan Örgütsel } \\
\text { Destek }\end{array}$ & $0,479^{* * *}$ & 0,52 & 0,37 & 0,58 \\
\hline Algılanan Örgütsel Destek & $--->$ & $\begin{array}{l}\text { Çalışan } \\
\text { Performansı }\end{array}$ & $0,510^{* * *}$ & 0,47 & 0,38 & 0,61 \\
\hline Dağıtımsal Adalet & $--->$ & $\begin{array}{l}\text { Çalışan } \\
\text { Performansı }\end{array}$ & & & & \\
\hline Toplam Etki (c) & & & 0,447 & 0,49 & 0,35 & 0,54 \\
\hline Doğrudan Etki (c') & & & $0,205^{* * *}$ & - & 0,12 & 0,30 \\
\hline Dolaylı Etki (axb) & & $0,242^{* * *}$ & - & 0,17 & 0,32 \\
\hline
\end{tabular}

Not: $n=353$ (5.000 Bootstrap Örneklem), YD \%95 GA = Yanlılığı düzeltilmiş \%95 Güven Aralığı, X= Dağıtımsal Adalet, $Y=$ Çalışan Performansı, $M=$ Algılanan Örgütsel Destek, $a=X$ değişkeninin $M$ değişkeni üzerindeki etkisi, $b=M$ değişkeninin $Y$ değişkeni üzerindeki etkisi, $c=X$ değişkeninin $Y$ değişkeni üzerindeki toplam etkisi, $c^{\prime}=X$ değişkeninin $Y$ değişkeni üzerindeki etkisi. $* * * p<0,001$

\section{Sonuç}

Dağıtımsal adaletin çalışan performansı üzerindeki etkisinde algılanan örgütsel desteğin aracılık rolünü belirlemek amacıyla Gaziantep ilindeki tekstil üretimi işletmelerinde yapılan bu araştırmada anket aracılığıyla toplanan veriler analiz edilmiştir.

Analiz neticesinde dağıtımsal adaletin algılanan örgütsel desteği pozitif yönde anlamlı olarak etkilediği tespit edilmiştir. Tespit edilen bu bulgu dağıtım adaletinin algılanan örgütsel destek üzerindeki 
etkisini tespit etmek amacıyla yapılan (Wayne, Shore, Bommer ve Tetrick 2002; DeConinck, 2010; Mitchell, Gagné, Beaudry ve Dyer, 2012) araştırma sonuçlarıyla uyumludur. Bu bulgu dağıtımsal adaletin algılanan örgütsel desteği arttırdığını göstermektedir. Loi vd.'nin (2006) de belirttiği gibi çalışan-örgüt ilişkisinde dağıtım adaleti ile çalışanların sosyo-duygusal ihtiyaçlarının karşılanması, algılanan örgütsel destek düzeyini arttırmaktadır. Bu bulgu Cropanzano vd. (2002) ve Ambrose ve Schminke'nin (2003) sosyal değişim teorisi çerçevesinde gerek ekonomik fayda odaklı etkileşim ile gerekse de sosyo-duygusal intiyaçların karşılanmasına yönelik olarak çalışan-örgüt etkileşiminde olumlu adalet algısının algılanan örgütsel desteği etkilediği görüşlerine katkı sunmaktadır. Ayrıca bu bulgu çalışanlarda oluşan adil muamele algısı (Eisenberger vd., 1986) ve örgütsel destek ilişkisinde Shore ve Shore'ın (1995) ifade ettiği gibi “kaynakların adil dağılımına ilişkin dağıtım adaleti algısı algılanan örgütsel desteğin bir beliryecisidir" ifadesine katkı sunmaktadır. Tespit edilen bu bulguya göre, örgütlerde dağıtım adaleti ile çalışanların sosyo-duygusal ihtiyaçlarının karşılanabileceği değerlendirmesi yapılabilmektedir.

Araştırmanın ana amacına yönelik yapılan dağııımsal adaletin çalışan performansı üzerindeki etkisinde algılanan örgütsel desteğin aracı rolünün tespit edilmesine yönelik yapılan analiz neticesinde ise dağıtımsal adaletin çalışan performansı üzerindeki etkisinde algılanan örgütsel desteğin kısmi aracı rolü tespit edilmiştir. Tespit edilen bu bulgu dağıtımsal adaletin çalışan performansı üzerindeki etkisinde algılanan örgütsel desteğin arttıııı rolü olduğunu göstermektedir. Bu bulgu sosyal değişim teorisi çerçevesinde çalışanlar performanslarını örgütsel kazanımlara göre şekillendirdikleri için (Kaplan ve Öğüt, 2012) çalışanörgüt etkileşiminde çalışanların çabalarının örgüt nezdinde faydalı olduğu inancının oluşmasıyla bu faydaya çabayla karşılık verdikleri için (Rhoades ve Eisenberger, 2002; Turunç ve Çelik, 2010) olumlu dağıtımsal adalet algısının çalışan performansı üzerindeki etkisinde algılanan örgütsel desteğin güçlendirici etkisini göstermektedir. Yine tespit edilen bu bulguya göre dağıtım adaleti ile birlikte çalışanların sosyo-duygusal intiyaçlarıın karşılanmasının çalışan performansını arttırdığı değerlendirmesi yapılabilmektedir. Ancak tüm elde edilen bulguların seçilen örneklem, tercih edilen anket tekniği, kesitsel araştırma sınırlılıkları çerçevesinde değerlendirilmesi gerekmektedir.

Bu çalışmanın literatüre en önemli katkısının dağıtımsal adaletin çalışan performansı üzerindeki etkisinde algılanan örgütsel desteğin arttırıcı bir etkisi olduğunu kanıtlamasıdır. Bu açıdan bu çalışmanın literatüre katkı sağlayacağı değerlendirilmesi yapılmaktadır. Gelecekte yapılacak çalışmalar için ise etkileşimsel adalet, işlemsel adalet ve dağıtımsal adalet gibi değişkenlerin iş tatmini ve çalışan performansı üzerindeki etkisinde lider-üye etkileşiminin aracı değişken olarak ele alan çalışmaların yapılmasını önerilmektedir. Uygulayıcılara yönelik ise, iş yerinde ücrete yönelik olumlu adalet algısının çalışan-örgüt etkileşiminde önemli bir etken olduğu gerçeğinin göz önünde bulundurulması gerektiği önerisi yapılmaktadır. Ayrıca çalışan performansının yükseltilmesi için ise öncelikle adil yönetim uygulamalarıyla çalışanların iş tatmin düzeylerini arttıracak çalışmaların yapılması tavsiye edilmektedir.

\section{Beyan ve Açıklamalar (Disclosure Statements)}

1. Bu çalışmanın yazarları, araştırma ve yayın etiği ilkelerine uyduklarını kabul etmektedirler (The authors of this article are admitted that they complied with the principles of research and publication ethics).

2. Yazarlar tarafından herhangi bir çıkar çatışması beyan edilmemiştir (No potential conflict of interest was reported by the authors).

3. Bu çalışma, intihal tarama programı kullanılarak intihal taramasından geçirilmiştir (This article was screened for potential plagiarism using a plagiarism screening program). 


\section{Kaynaklar}

Ambrose, M. L., \& Schminke, M. (2003). Organization structure as a moderator of the relationship between procedural justice, interactional justice, perceived organizational support, and supervisory trust. Journal of applied psychology, 88(2), 295.

Aslan, H., \& Uçar, M. (2015). The effect of organizational justice on turnover intentions: A field study in Gaziantep. Journal of socıal science research, 9(3), 1911-1919.

Başa, Z. (2019). Yönetici eğitim düzeyinin çalışan performansına etkisi: Kahramanmaraş tekstil sanayi örneği. Selçuk Üniversitesi, Sosyal Bilimler Enstitüsü, Yüksek Lisans Tezi, Konya.

Cheung, M. F., \& Law, M. C. (2008). Relationships of organizational justice and organizational identification: The mediating effects of perceived organizational support in Hong Kong. Asia Pacific Business Review, 14(2), $213-231$.

Chiang, C. F., \& Hsieh, T. S. (2012). The impacts of perceived organizational support and psychological empowerment on job performance: The mediating effects of organizational citizenship behavior. International Journal of Hospitality Management, 31(1), 180-190.

Choi, S. (2011). Organizational justice and employee work attitudes: The federal case. The American Review of Public Administration, 41(2), 185-204.

Clay-Warner, J., Reynolds, J., \& Roman, P. (2005). Organizational justice and job satisfaction: A test of three competing models. Social Justice Research, 18(4), 391-409.

Cohen-Charash, Y., \& Spector, P. E. (2001). The role of justice in organizations: A meta-analysis. Organizational Behavior and Human Decision Processes, 86, 278-321.

Cropanzano, R., Prehar, C. A., \& Chen, P. Y. (2002). Using social exchange theory to distinguish procedural from interactional justice. Group \& Organization Management, 27(3), 324-351.

Crow, M. S., Lee, C. B., \& Joo, J. J. (2012). Organizational justice and organizational commitment among South Korean police officers: An investigation of job satisfaction as a mediator. Policing: An International Journal of Police Strategies \& Management, 35(2), 402-423.

Çınar, Ö. (2013). Yapısal eşitlik modellemesi ile iş tatmini, örgütsel bağlılık, örgütsel destek ve örgütsel adaletin örgütsel çıktılar üzerindeki etkisinde örgütsel vatandaşlık davranışının aracılık rolü: Kahramanmaraş bankacılık sektöründe bir alan araştırması. Kahramanmaraş Sütçü İmam Üniversitesi, Sosyal Bilimler Enstitüsü, Doktora Tezi.

Çöl, G. (2008). Algılanan güçlendirmenin iş gören performansı üzerine etkileri. Doğuş Üniversitesi Dergisi, 9(1), 35-46.

DeConinck, J. B. (2010). The effect of organizational justice, perceived organizational support, and perceived supervisor support on marketing employees' level of trust. Journal of Business Research, 63(12), 1349-1355.

Eisenberger, R., Huntington, R., Hutchison, S., \& Sowa, D. (1986). Perceived organizational support. Journal of Applied Psychology, 71(3), 500-507.

Foley, S., Deborah L. K., \& Gary N. P. (2002). The perceived glass ceiling and justice perceptions: An investigation of hispanic law associates. Journal of Management, 28(4), 471-496.

Greenberg, J., \& Baron A. (2000). Behavior in organizations (7th ed.). Englewood Cliffs, NJ: Prentice-Hall.

Gürbüz, S., \& Şahin, F. (2016). Sosyal bilimlerde araştırma yöntemleri felsefe, yöntem, analiz (3. bs.). Ankara: Seçkin Yayıncılık.

Gürbüz, S., \& Mert, I. S. (2009). Validity and reliability testing of organizational justice scale: An empirical study in a public organization. Review of Public Administration, 42(3), 117-139.

Haar, J. M., \& Spell, C. S. (2009). How does distributive justice affect work attitudes? The moderating effects of autonomy. The International Journal of Human Resource Management, 20(8), 1827-1842.

İçerli, L. (2010).Örgütsel adalet: Kuramsal bir yaklaşım. Girişimcilik ve Kalkınma Dergisi, (5:1), 67-92.

İraz, R., \& Akgün, Ö. (2011). Örgütsel bağlılığın çalışma performansına üzerine ölçmeye yönelik bir çalışma. Selçuk Üniversitesi Sosyal Bilimler Meslek Yüksek Okulu Dergisi, 14(1-2), 225-250.

İşcan, Ö., F. \& Naktiyok, A. (2004). Çalışanların örgütsel bağdaşımlarının belirleyicileri olarak örgütsel bağlılık ve örgütsel adalet algıları. Ankara Üniversitesi Siyasal Bilgiler Fakültesi Dergisi, 59(1), 181-201.

Kalay, F. (2016). İşletmelerde örgütsel adaletin işgören performansı üzerindeki etkisi: Teorik bir inceleme. Kastamonu Üniversitesi iktisadi ve Idari Bilimler Fakültesi Dergisi, 11(1), 147-158. 
Kaplan, M., \& Öğüt, A. (2012). Algılanan örgütsel destek ile örgütsel bağlılık arasındaki ilişkinin analizi: Otel işletmelerinde bir uygulama. Süleyman Demirel Üniversitesi Iktisadi ve Idari Bilimler Fakültesi Dergisi, 17(1), 387401.

Kim, S. J., \& Chung, E. K. (2019). The effect of organizational justice as perceived by occupational drivers on traffic accidents: Mediating effects of job satisfaction. Journal of Safety Research, 68, 27-32.

Kirkman, B. L., \& Rosen, B. (1999). Beyond self-management: Antecedents and consequences of team empowerment. Academy of Management Journal, 42(1), 58-74.

Loi, R., Hang-Yue, N., \& Foley, S. (2006). Linking employees' justice perceptions to organizational commitment and intention to leave: The mediating role of perceived organizational support. Journal of Occupational and Organizational Psychology, 79(1), 101-120.

Meydan, C. H., Basım, H. N., \& Çetin, F. (2011). Örgütsel adalet algısı ve örgütsel bağlılığın tükenmişlik üzerine etkisi: Türk kamu sektöründe bir araştırma. Türk Dünyası Sosyal Bilimler Dergisi, (57), 175-200.

Meydan, C. H., \& Şeşen, H. (2015). Yapısal eşitlik modellemesi: AMOS uygulamaları (2.Baskı). Ankara: Detay Yayıncılık.

Mitchell, J. I., Gagné, M., Beaudry, A., \& Dyer, L. (2012). The role of perceived organizational support, distributive justice and motivation in reactions to new information technology. Computers in Human Behavior, 28(2), 729-738.

Nasurdin, A. M., \& Khuan, S. L. (2007). Organizational justice as an antecedent of job performance. Gadjah Mada International Journal of Business, 9(3), 335-353.

Neves, P., \& Eisenberger, R. (2012). Management communication and employee performance: The contribution of perceived organizational support. Human performance, 25(5), 452-464.

Niehoff, B .P., \& Moorman, R. H. (1993). Justice as a mediator of the relationship between methods of monitoring and organizational citizenship behavior. Academy of Management Journal, 36(3), 527-556.

Ouyang, Z., Sang, J., Li, P., \& Peng, J. (2015). Organizational justice and job insecurity as mediators of the effect of emotional intelligence on job satisfaction: A study from China. Personality and Individual Differences, 76, 147152.

Polat, S., \& Celep, C. (2008). Ortaöğretim öğretmenlerinin örgütsel adalet, örgütsel güven, örgütsel vatandaşlık davranışlarına ilişkin algıları. Kuram ve Uygulamada Eğitim Yönetimi, 54(54), 307-331.

Ponnu, C. H., \& Chuah, C. C. (2010). Organizational commitment, organizational justice and employee turnover in Malaysia. African Journal of Business Management, 4(13), 2676-2692.

Rhoades, L., \& Eisenberger, R. (2002). Perceived organizational support: A review of the literature. Journal of Applied Psychology, 87(4), 698-714.

Rhoades, L., Eisenberger, R., \& Armeli, S. (2001). Affective commitment to the organization: The contribution of perceived organizational support. Journal of applied psychology, 86(5), 825-836.

Shore, L. M., \& Shore, T. H. (1995). Perceived organizational support and organizational justice. In R. Cropanzano, \& M. Kacmar (Eds.), Organizational politics, justice and support: Managing the social climate in the work place (pp. 149-164). Westport, CT: Quorum.

Sigler, T. H., \& Pearson, C. M. (2000). Creating an empowering culture: Examining the relationship between organizational culture and perceptions of empowerment. Journal of Quality Management, 5(1), $27-52$.

Sökmen, A., Bilsel, M. A., \& Erbil, C. (2013). Örgütsel adaletin çalışan motivasyonu ve performansı üzerindeki etkisi: Bankacılık sektöründe bir araştırma. Gazi Üniversitesi Iktisadi ve Idari Bilimler Fakültesi Dergisi, 15(1), 43-62.

Suliman, A., \& Al Kathairi, M. (2012). Organizational justice, commitment and performance in developing countries: The case of the UAE. Employee Relations, 35(1), 98-115.

Turunç, Ö., \& Çelik, M. (2010). Çalışanların algıladıkları örgütsel destek ve iş stresinin örgütsel özdeşleşme ve iş performansına etkisi. Yönetim ve Ekonomi: Celal Bayar Üniversitesi iktisadi ve Idari Bilimler Fakültesi Dergisi, 17(2), 183-206.

Uppal, N. (2017). Moderation effects of perceived organisational support on curvilinear relationship between neuroticism and job performance. Personality and Individual Differences, 105, 47-53.

Wang, X., Liao, J., Xia, D., \& Chang, T. (2010). The impact of organizational justice on work performance: Mediating effects of organizational commitment and leader-member exchange. International Journal of Manpower, 31(6), 660-677.

Wayne, S. J., Shore, L. M., Bommer, W. H., \& Tetrick, L. E. (2002). The role of fair treatment and rewards in perceptions of organizational support and leader-member exchange. Journal of Applied Psychology, 87(3), 590. 
Yeniçeri, Ö., Demirel, Y., \& Seçkin, Z. (2009). Örgütsel adalet ile duygusal tükenmişlik arasındaki ilişki: İmalat sanayi çalışanları üzerine bir araştırma. Karamanoğlu Mehmetbey Üniversitesi Sosyal ve Ekonomik Araştırmalar Dergisi, 2009(1), 83-99.

Zeinabadi, H., \& Salehi, K. (2011). Role of procedural justice, trust, job satisfaction, and organizational commitment in organizational citizenship behavior (OCB) of teachers: Proposing a modified social exchange model. ProcediaSocial and Behavioral Sciences, 29, 1472-1481. 